\title{
Experimental analysis of new interfaces for connections by adhesion, interlocking and friction
}

\author{
*Diógenes, Hidelbrando J. F. ; El Debs, Ana Lúcia H. C. ${ }^{2}$; Valente, Isabel B. ${ }^{3}$ \\ (1) PhD. Assistant Professor, Federal Rural University of Semi-arid, Angicos, Brazil. \\ e-mail: hidelbrando.diogenes@ufersa.edu.br \\ Gamaliel Martins Bezerra, Angicos, RN, Brazil. \\ +55849905 5371 \\ *Corresponding author \\ (2) PhD. Associated Professor, University of Sao Paulo, São Carlos, Brazil. \\ e-mail: analucia@sc.usp.br \\ Trabalhador São Carlense, 400 - São Carlos - SP - Brazil \\ (3) PhD. Assistant Professor, ISISE, Civil Engineering Department, Engineering School, University of Minho, \\ Guimarães, Portugal. \\ e-mail: isabelv@ civil.umiho.pt \\ Campus de Azurém - 4800-058 Guimarães, Portugal
}

\begin{abstract}
This paper presents the results of an experimental program developed to investigate the behavior of an innovative technology for connections by adhesion, interlocking and friction in composite structures. Connections have a strategic importance for precast concrete and steel-concrete composite structures, since they determine the global structural behavior and affect the whole production process, from execution to assemblage and other services on site. Currently, however, steel-concrete composite connections are not completely adapted for their use in prefabricated slabs. In this way, the development of new types of connections is clearly necessary, where connections by adherence (or connections by adhesion, interlocking and friction) seem quite promising. To improve the knowledge in the field of connections by adherence, this paper proposes a new geometry of embossments in the steel and in the concrete surfaces associated with the use of a high performance mortar. Monotonic push-out tests are performed, and their results are presented and discussed. A satisfactory behavior of the proposed connection in terms of strength is observed, justifying further studies on the subject.
\end{abstract}

Keywords: Composite structures; connection by adhesion, interloking and friction; push-out test. 


\section{CONTEXT AND MOTIVATION}

Due to the irreversible process of industrialization of construction demanded by the post Second World War in Europe and, nowadays ,by the growing demand for infrastructure in countries with emerging markets, the search for building systems with a high level of prefabrication is a reality. In this context, steel and concrete composite structures can provide very competitive solutions, once they are adaptable to a process of prefabrication, in which whole or part of the structural elements may be produced in an industrial environment, and not on site.

Composite structural systems made of steel and concrete aim to extract maximum performance of each material. Therefore, it is necessary to ensure the best possible interaction between the steel element and the concrete component. A composite action can be obtained by limiting the relative displacement at the interface between steel and concrete through the use of shear connectors.

Currently, steel and concrete composite connections are not yet completely adapted to be used in prefabricated slabs. For example, to achieve composite action, the commonly used connection consists in a group of headed studs that are welded to the upper flange of the steel beam and then connected to the slab, when the pockets in the slab are concreted on site. This solution presents several disadvantages [1]: numerous small quantities of concrete need to be poured on site to fill the pockets which slows down the construction progress and cracks may develop in the corners of the pockets, increasing the risk of degradation by corrosion for both the slab reinforcement and the connection itself. 
In this context, the development of new types of connections is clearly necessary aiming to reduce the construction time and to improve the building durability, without increasing the cost of the solution.

Thus looking for a practical, economical and fast solution for connections in steel and concrete composite structures, connections by adhesion, interlocking, and friction, first presented and studied by Thomann [2], seem quite promising.

Basically, the innovative connection (Figure 1 - (a)) is constituted by two embossed steel plates (Figure 1 -(b)), welded "back-to-back" to each other, and welded longitudinally to the upper flange of the steel girder.

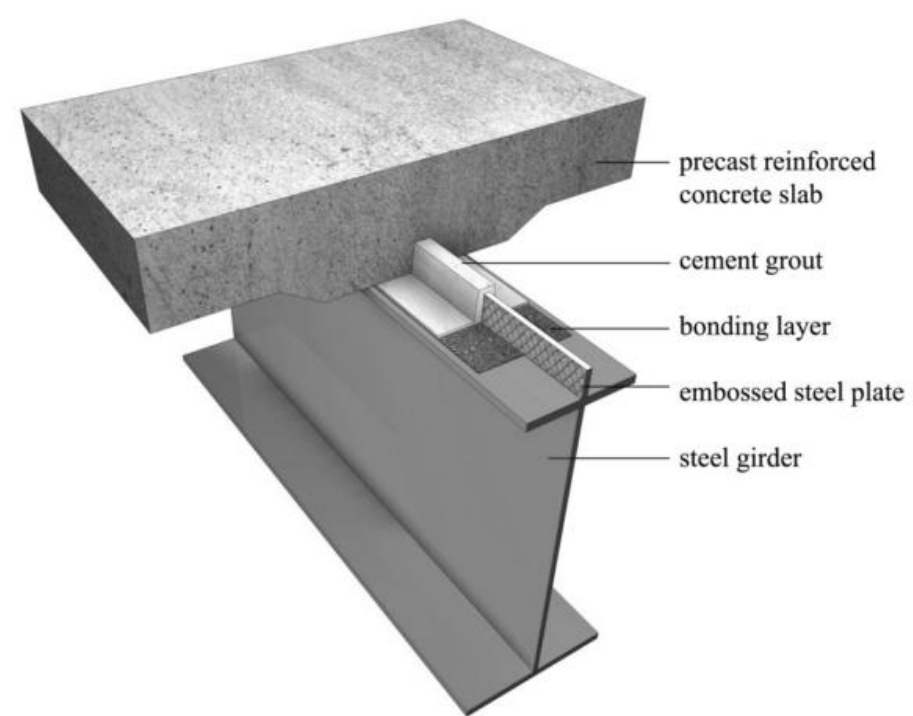

(a)
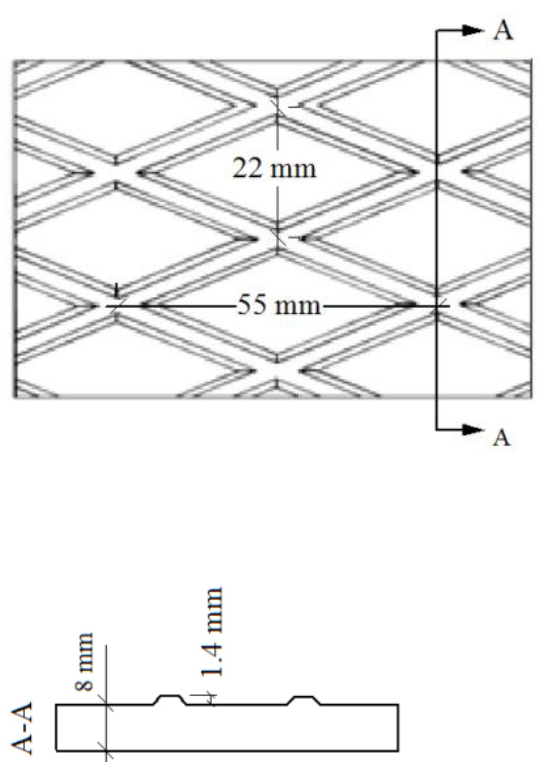

(b)

Figure 1 - (a) Connection by adhesion, interlocking and friction [3]; (b) Employed embossed steel plate (BRI 8/10)[4]

A "bonding layer" is created on the external face of the upper flange by disposing an adhesive film with sand. The deck consists of precast reinforced concrete segments which 
are fabricated with an inner rib at the lower part. The surface of this inner rib is roughened by using a retarding agent during casting followed by hydro-jetting or sandblasting.

The slab segments are positioned over the steel connector and the void is filled with injected high strength cement grout. Once the cement grout is cured, the connection is activated and the structural element becomes composite.

The resistance of the connection is sourcing from the shear stress developed in three types of interfaces: the embossed steel-cement grout interface, the cement grout-rough concrete interface and finally the interface between cement grout and the bonding layer (Figure 1).

According to Papastergiou and Lebet [1] and Thomann and Lebet [2], the main advantages of connections by adhesion, interlocking and friction, is due to the fact that they present a high resistance to shear, which provides a high level of connection (related to the proportion of displacements between the interfaces) on the composite section and they present also a very stiff behavior which provides a high level of interaction. This indicates that the initial premise for a composite action, a small relative displacement between the interfaces is valid, and therefore the connection is possible. Furthermore, the presence of continuous embossed steel plates welded along the upper flange, contributes to:

a. a higher strength of the steel beam;

b. does not create concentration of stress in the connection region, thus minimizing problems of durability caused by cracking when compared to headed studs. 
However, it is important to note that the cost of these advantages is reflected in the behavior of the connection in relation to ductility, once connections by shear presents brittle behavior usually.

Thus aiming to explore the field of connections by adhesion, interlocking and friction, this paper proposes a new geometry of embossment for the interfaces involved in the connection associated with the use of a high performance mortar (HPM) to connect these materials.

These new solutions for the connections aim to provide an easier way to produce adequate interfaces. Basically, the proposal consists in producing a regular embossment in the surface of concrete slab and more deep ribs in the shear connector surface, besides establishing the angle of $45^{\circ}$ to the direction of the ribs in the connector surface.

Figure 2 highlights the principal alterations introduced in the actual solution for the interfaces, in comparison to the previous solution adopted in [1] and [2].

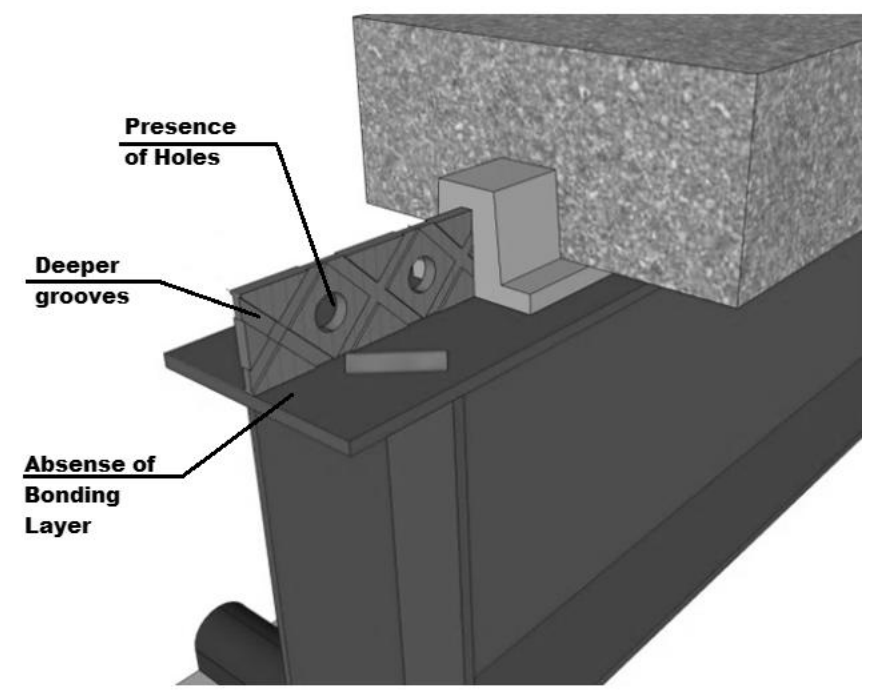

Figure 2 - New proposal for the connection 


\subsection{Brief review}

Several shear connectors have been proposed, and many types are currently used in composite structures. However, many of them have significant restrictions in terms of industrial production, installation and structural behavior. In building structures, the most usually employed shear connectors are stud and U-laminated. In bridge structures are also employed others specials connectors as for example Shim, Lee, and Chang [5], Studnicka et al. [6], Baran and Topkaya [7], Kim et al. [8], Schmitt et al. [9], and Vellasco et al. [10].

Nowadays, the most widespread connector is the headed stud developed by Nelson Stud Welding, in the 40s. For composite floors, the connection between the concrete slab and the steel framework made with studs is used worldwide. Although they are "easy" to install, it is usually necessary to have a high amount because its isolated shear strength is relatively small.

Regarding the U-laminated connectors, they are still used in Brazil but in disuse in other industrialized countries. It consists basically on a piece of laminated U profile with one of the flanges welded to the steel profile. Although they have a lower productivity in terms of welding process than stud during installation, they have a similar structural behavior. It is noteworthy that the isolated resistance is higher in U-connectors than in studs.

As an alternative to pin-type connectors, as studs and U-laminated connectors, at the end of the 80 s the German engineering company Leonhardt, Andrä and Partners presented the Perfobond connector, initially for use in bridges and only from 90s focused for use in buildings [11]. It consists on a continuous metallic plate with holes, welded to the upper flange of steel beam and embedded inside the concrete slab. During casting, the plate 
openings are filled with concrete, forming dowels that provide resistance to horizontal shear and prevent vertical separation between the steel beam and the concrete slab.

The mechanical behavior of Perfobond is associated with four main phenomena: (a) the shear strength of the concrete slab, (b) the effect of transverse reinforcement in the slab, (c) the resistance of the connector plate itself and (d) the shear strength of the concrete confined within the holes of the connector [11].

The Perforbond presents a rigid behavior for service loads and a ductile behavior in the ultimate limit state. This connector is also adequate to be used in bridges due to the good behavior under fatigue loadings [12]. However, it is necessary to concrete the slab in situ and it is not possible to use prefabricated concrete elements.

The spread of Perfobond type connectors trough the world, allowed the proposition of other arrangements for this connector and the beam-to-slab connection. As an example can be mentioned the Crestbond connector [11], which solves partially the passage of reinforcements trough the connector and more recently, the connections by adherence that enabled the use of continuous connectors with prefabricated slabs.

The study of connections by adherence, between steel-concrete composite structures, is relatively new. In 2002, the Steel Structures Laboratory of EPFL in Switzerland associated with the engineering bureau DIC Engineers began to develop an innovative connection for the beam-slab connection, which they called "Connection by Adherence". This new connection was experimentally and analytically studied by Thomann [3].

The new term "Connection by Adhesion, Interlocking and Friction", was later adopted by Papastergiou [4]. This differentiation from the term adopted by Thomann [3] is due to the fib Model Code [13] which recommends a specific denomination for each resistance 
mechanism present in the connection. Thus, as the proposed connection is based on adhesion, interlocking and friction at the same time, the new name proposed by Papastergiou [4] seems to be the one which best represents the connection characteristics. The work of Thomann [3] comprised extensive numerical and experimental research, using data obtained in push-out tests, direct shear tests, pull-out tests, and composite beams tests. Thomann [3] was able to demonstrate the viability of the new connection system and proposed requirements for a specific geometry of embossments, mainly for static and long term loadings. It should be noted that the work of Thomann [3] envisioned the use of this type of connection in composite bridges, structures which are necessarily subjected to repeated loadings and where fatigue phenomena are involved.

Papastergiou [4] continued the work of Thomann [3] and analyzed the fatigue behavior of this type of connection. However, due to the high stiffness occasioned by the "bond layer", Papastergiou [4] preferred to eliminate this "bond layer" in his study.

Two important remarks from the cyclic Push-out tests performed by Papastergiou [4], is that: first, once slip reaches the value of slip at failure for monotonic loading, the connection continues to resist loads, but with increasing slip, and any further cyclic loading is limited to only few hundred cycles; second, in fact the uplift during cyclic loading, while no failure occurs, remains lower than the uplift which corresponds to the failure for static loading.

To exemplify the difference between these alternatives in terms of strength, Figure 3 compares the typical shear force-slip curves of these innovative connections with the shear force-slip curves obtained with headed Studs and Perfobond connector. All the tested push-out specimens were made of two precast concrete elements that are connected 
to the steel connectors with an injection of cement paste of compressive strength $f_{c}=80$ $\mathrm{N} / \mathrm{mm}^{2}$. The connection with headed studs comprises 9 studs with $22 \mathrm{~mm}$ diameter per meter, while the Perfobond connection is made of a steel plate with 14 holes of $50 \mathrm{~mm}$ diameter per meter.

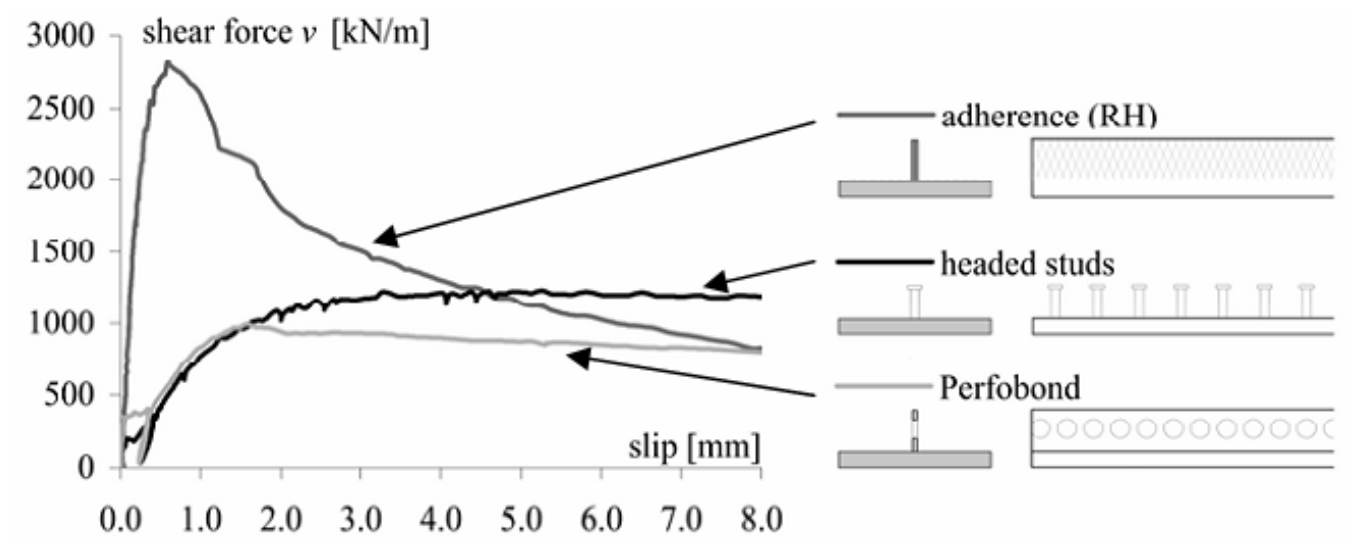

Figure 3 - Structural performance of innovative connections and shear studs [14]

Another particularity of Papastergiou [4] works was the use of ultra-high performance fiber reinforced concrete (UHPFRC) to manufacture some of the specimens. Besides the use of UHPFRC slabs, [4] apply an artificial rough surface in the inner rib, with conical pins of $8 \mathrm{~mm}$ diameter, using a proper formwork providing a roughness with controlled geometry.

In the present study, the connection load capacity is improved by considering circular holes regularly spaced along the shear connector. This idea reflects the behavior observed in Perfobond shear connectors, where part of the load carrying capacity results from the shear resistance of the confined concrete that lies inside the connector's openings [15] and [16]. In addition, friction portion is enhanced by the presence of the ribs on the connector and the roughness of the slab. 


\section{EXPERIMENTAL PROGRAM}

The next sections will describe the push-out tests performed in the Structures Laboratory at the School of Engineering of Sao Carlos, Brazil. These tests were performed in two stages. STAGE 1 corresponds to preliminary tests, which were intended to validate the best setup dispositions and identify possible problems in the manufacturing process or the specimen's configuration. STAGE 2 corresponds to the main push-out tests.

The push-out test was developed to simulate the transmission of forces on a composite beam. The specimen consists on a steel beam section held in the vertical position by two identical concrete slabs [17]. The connection between the concrete slab and the steel profile is accomplished with steel connectors. The forces are applied to the steel element. Shear stresses will develop along the existent interfaces, in order to transmit the load from the steel element to the blocks of reinforced concrete and from them to the base of the testing setup. 


\subsection{Specimens description}

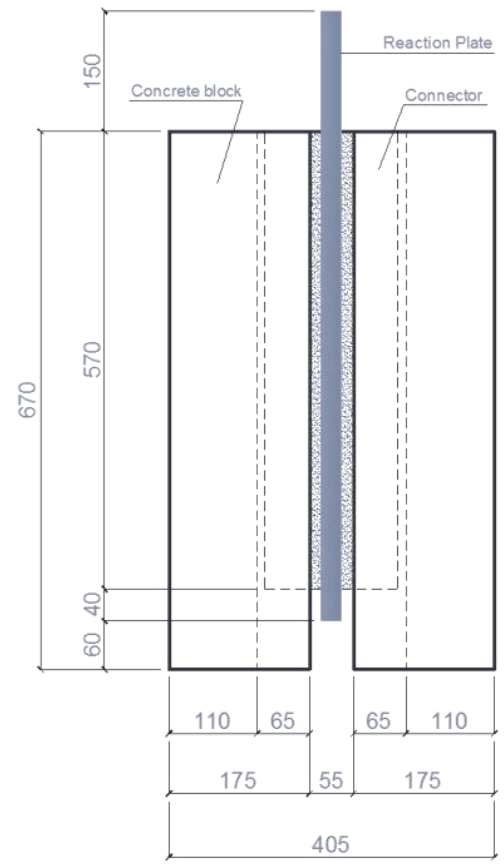

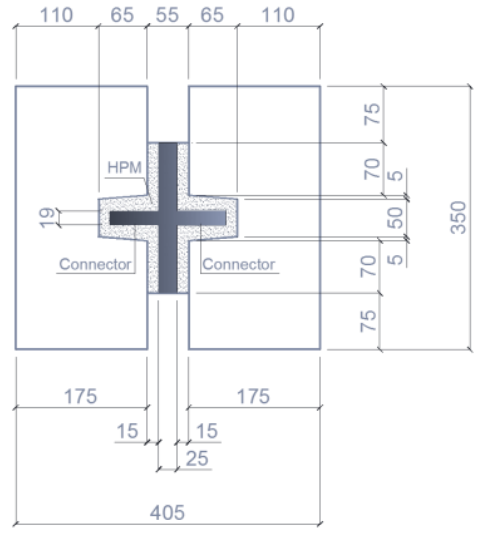

(b)

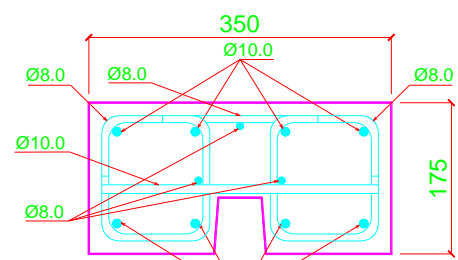

$\varnothing 10.0$

(a)

(c)

Figure 4 - Dimensions of standard specimen (mm): (a) View; (b) Cross section; (c) Reinforcements blocks at STAGE 2.

The specimens, Figure 4, consists of two pre-fabricated concrete blocks, assembled together with a continuous rib steel connector by filling the void between them with a cement mortar. In all reaction plates, $12.5 \mathrm{~mm}$ steel bars were welded on its surface in order to serve as spacers and provide the shear keys (Figure 5).

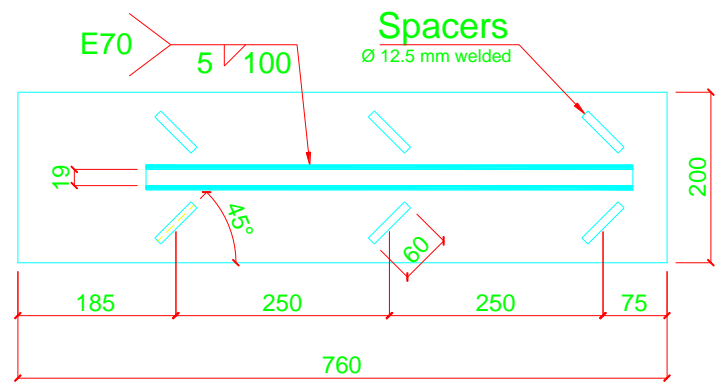

(a)

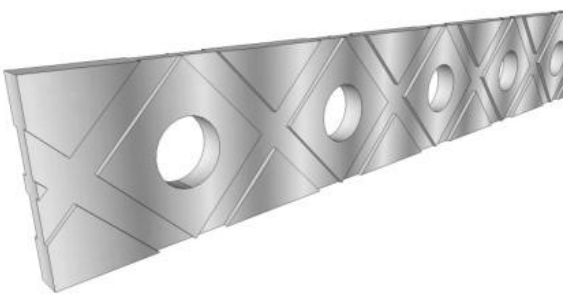

(b)

Figure 5 - (a) Standard dimensions of connectors + reaction plate; (b) 3D sketch of RP-type connector 
It should be noted that the option of not using the standard geometry proposed in the Eurocode 4 [17] was taken in order to compare the results with those obtained by Thomann [3] and Papastergiou [4].

In STAGE 1 the blocks were made of plain concrete, while in the STAGE2 the blocks were made of reinforced concrete. When the first stage of testing was prepared, it was not yet clear that the presence of the reinforcement is very important to absorb the transversal forces developed in the concrete slab. For this reason, it was decided to build these specimens without any reinforcement. Nevertheless, the results obtained with these specimens were useful to understand the specimens global behavior and to improve some aspects in the specimens prepared for STAGE 2.

As mentioned in item 1, the aim of the present work was to look for an easier way to produce shear connections in prefabricated elements and to adapt this new connection technology to the Brazilian market. Considering that a similar plate to BRI 8/10 used by Thomann [11] and Papastergiou [4] was not available in the local market, alternative kinds of embossment's were tested: L-type, R-type and RP-type. The difference between these connectors is a function of its embossments. The L-type connector did not receive mechanical or chemical treatment, as shown in Figure 6.a, i.e, it is a straight, plain and continuous steel plate. 


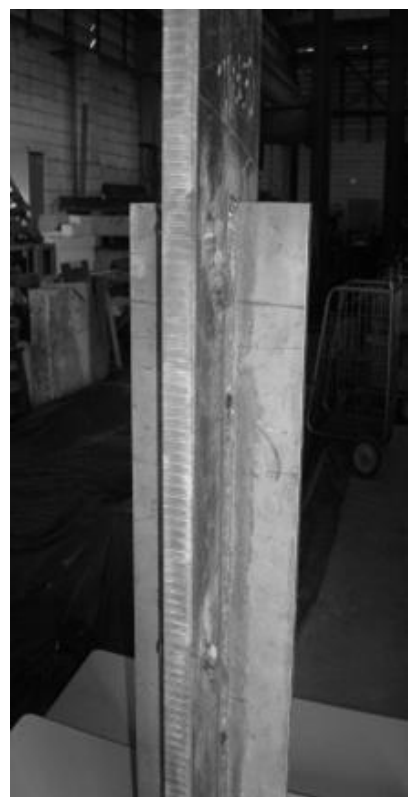

(a)

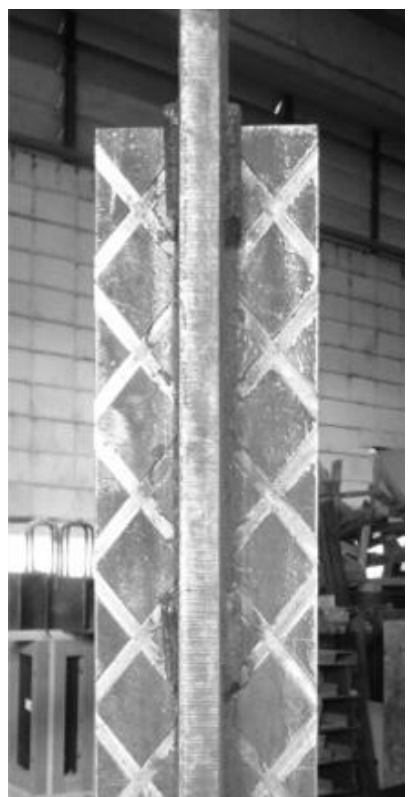

(b)

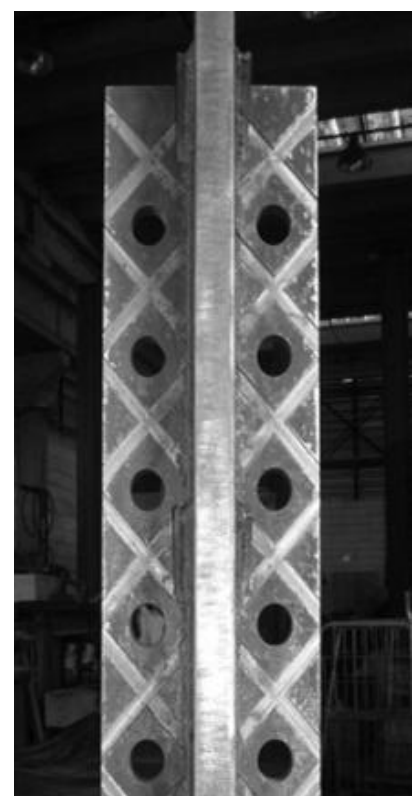

(c)

Figure 6-Connectors tested: (a) L-type connector; (b) R-type connector; (c) RP-type connector.

In contrast to the L connector, the R-type connector (Figure 6.b), received a mechanical treatment that consisted in creating superficial grooves with 45 degrees orientation, $2 \mathrm{~mm}$ depth and $10 \mathrm{~mm}$ width) to improve the mechanism of shear stresses transfer. Besides, a variation of the R-type connector was also proposed. The RP-type connector (Figure 6.c) is a combination of two ideas, the Perfobond proposed by Leonhardt [12] and the $\mathrm{R}$ connectors proposed by Thomann [3] . It is intended that the holes can generate a "dowel effect" that improves the connection shear strength.

Once a mechanical treatment was performed on the connector surface, a roughness was produced in the concrete blocks in order to provide the transfer of shear between the involved interfaces. The collage of a polka dot crosswalk automotive plastic (blanket), at the bottom of the formwork, allowed the printed roughness. Figure 7.a shows the obtained surface for the reinforced concrete block. 


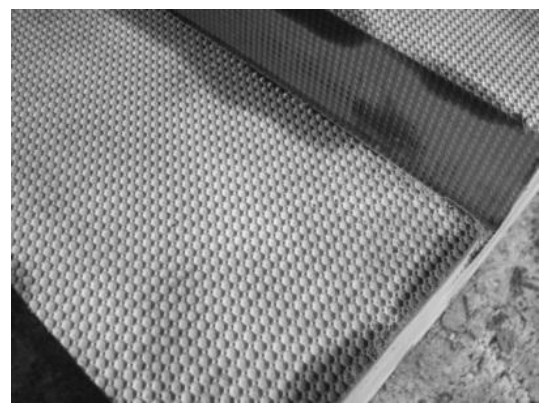

(a)

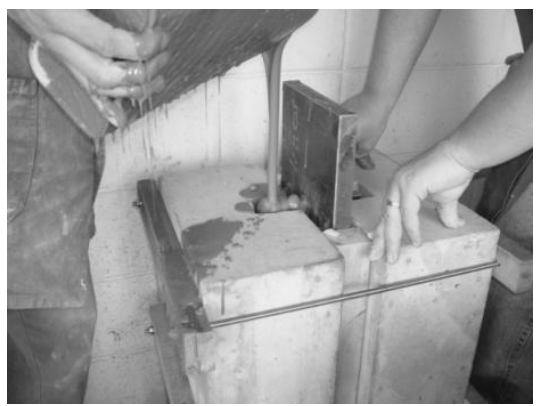

(c)

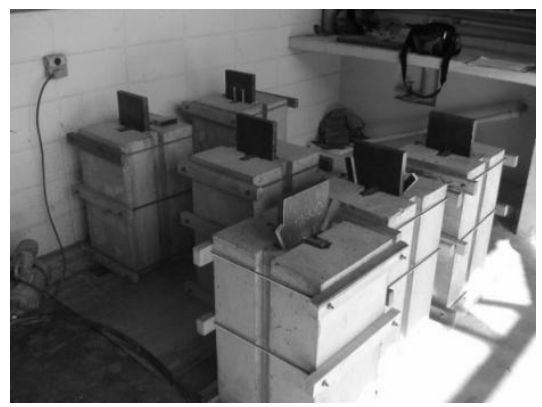

(b)

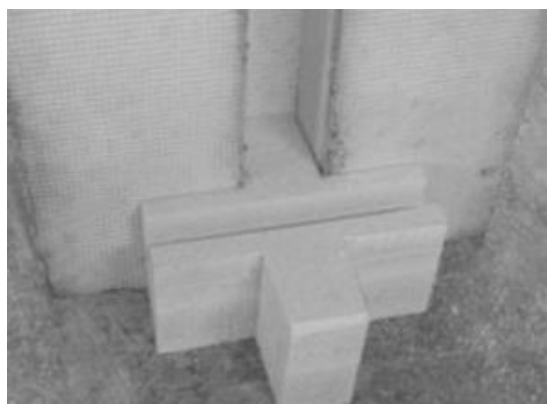

(d)

Figure 7- (a) printed roughness; (b) apparatus for grouting; (c) grouting process; (d) EPS formwork at the bottom of the sample.

The option for a "printing" roughness was taken in order to provide a greater uniformity on the surface. The use of retarders does not provide this uniformity, since the roughness is applied after the water blasting, removing the thin layer of mortar, thus exposing the aggregate and resulting in an irregular surface. In addition, the use of blankets in the formwork is easier and quicker to be done, since it only needs to be pasted at the bottom of the form and then a mold release agent is applied. The used blanket had a nominal depth of $1.2 \mathrm{~mm}$, which according to fib Model Code [13] configures itself as a smooth surface. Figure 7.b to Figure 7.d show the apparatus developed for the samples grouting. The tests were performed in pairs of specimens for each type of analyzed embossment, L, $\mathrm{R}$ and $\mathrm{RP}$, in a total of twelve specimens divided in two series, where six specimens were tested in Stage 1 and other six specimens were tested in Stage 2. Monotonic tests using displacement control were carried out aiming to evaluate the ultimate strength of the 
connection, to obtain the complete load-slip curve and to analyze the relation between uplift and slip.

\subsection{Materials properties}

The obtained mortar was based on the work developed by Vanderlei [18] which was devoted to the study of Reactive Powder Concrete (RPC). The RPC is basically composed of powders (quartz sand, cement common quartz powder and silica), small steel fibers, superplasticizer and water, where all solids have sizes that are smaller than $2 \mathrm{~mm}$. RPC is usually manufactured under similar conditions to conventional concrete, but with a very low $w / c$ ratio of around 0.15 .

In the Brazilian market, it is not easy to obtain industrialized mortars with compressive strength of about $80 \mathrm{MPa}$ and fluid as the ones used by Thomann [3], [4]. In order to obtain a fluid and injectable mortar, a mixture of RPC with $w / c$ ratio equal to 0.5 was developed. This mortar was called High Performance Mortar (HPM), since the used water/cement ratio was not compatible with the $w / c$ ratio of a RPC. It is noteworthy that HPM must have sufficient fluidity and workability to permit its injection in openings of about 15-20 mm wide.

Table 1 summarizes the mechanical properties of all the materials used in the connection which are concrete, steel and HPM. The concrete and HPM, compressive strength, elasticity modulus and tensile strength, was obtained from cylindrical samples, using the recommendations of ABNT-NBR-8522: 2008 [19] and ABNT-NBR-7222: 2014 [20]. 
Table 1 - Materials properties

\begin{tabular}{|c|c|c|c|c|c|}
\hline \multirow{3}{*}{\multicolumn{2}{|c|}{ Specimens }} & \multicolumn{3}{|c|}{ STAGE 1} & STAGE 2 \\
\hline & & P01 & P03 & P05 & \multirow{3}{*}{ P07 to P12 } \\
\hline & & P02 & P04 & P06 & \\
\hline Connecto & & $\mathbf{L}$ & $\mathbf{R}$ & $\mathbf{R P}$ & \\
\hline \multirow{3}{*}{$\begin{array}{l}\text { Concrete } \\
{\left[\mathrm{N} / \mathbf{m m}^{2}\right]}\end{array}$} & $f_{c m}$ & 54.4 & 45.2 & 47.7 & 38.76 \\
\hline & $f_{c t m}$ & 3.8 & 2.7 & 3.0 & 3.16 \\
\hline & $\boldsymbol{E}_{c m}$ & 45.9 & 42.9 & 35.3 & 34.02 \\
\hline \multirow{3}{*}{$\begin{array}{l}\text { HPM } \\
{\left[\mathbf{N} / \mathbf{m m}^{2}\right]}\end{array}$} & $f_{c m}$ & 75.9 & 75.9 & 87.2 & 76.37 \\
\hline & $f_{c t m}$ & 3.1 & 3.1 & 3.0 & 2.57 \\
\hline & $\boldsymbol{E}_{c m}$ & 24.9 & 24.9 & 28.01 & 28.81 \\
\hline \multirow{2}{*}{\multicolumn{2}{|c|}{$\begin{array}{l}\text { Steel } \\
{\left[\mathbf{N} / \mathbf{m m}^{2}\right]}\end{array}$}} & \multicolumn{4}{|c|}{ ASTM A-36 } \\
\hline & & \multicolumn{4}{|c|}{$f_{y}=250 \mathrm{~N} / \mathrm{mm}^{2} ; f_{u}=400 \mathrm{~N} / \mathrm{mm}^{2}$} \\
\hline
\end{tabular}

\subsection{Test setup and loading procedures}

The instrumentation used in the performed push-out tests is presented in Figure 8 .b. Resistive transducers were used to measure slip and uplift. Slip measurements were taken in both sides of the specimens, at the top of the prototype (Y-1 and Y-2) and at half of its height (Y-9, Y-10, Y11 and Y-11). Concerning the uplift measures, they were captured at the top (X-3 and X5, X-4 and X-6) and bottom (X-7 and X-8) of the prototype.

The push-out tests were carried out with displacement control at a loading speed of $0.004 \mathrm{~mm} / \mathrm{s}$ until the maximum load capacity was reached. Afterwards, a loading speed of $0.016 \mathrm{~mm} / \mathrm{s}$ was imposed until failure. An overview of the test setup is given in Figure 8.a. 

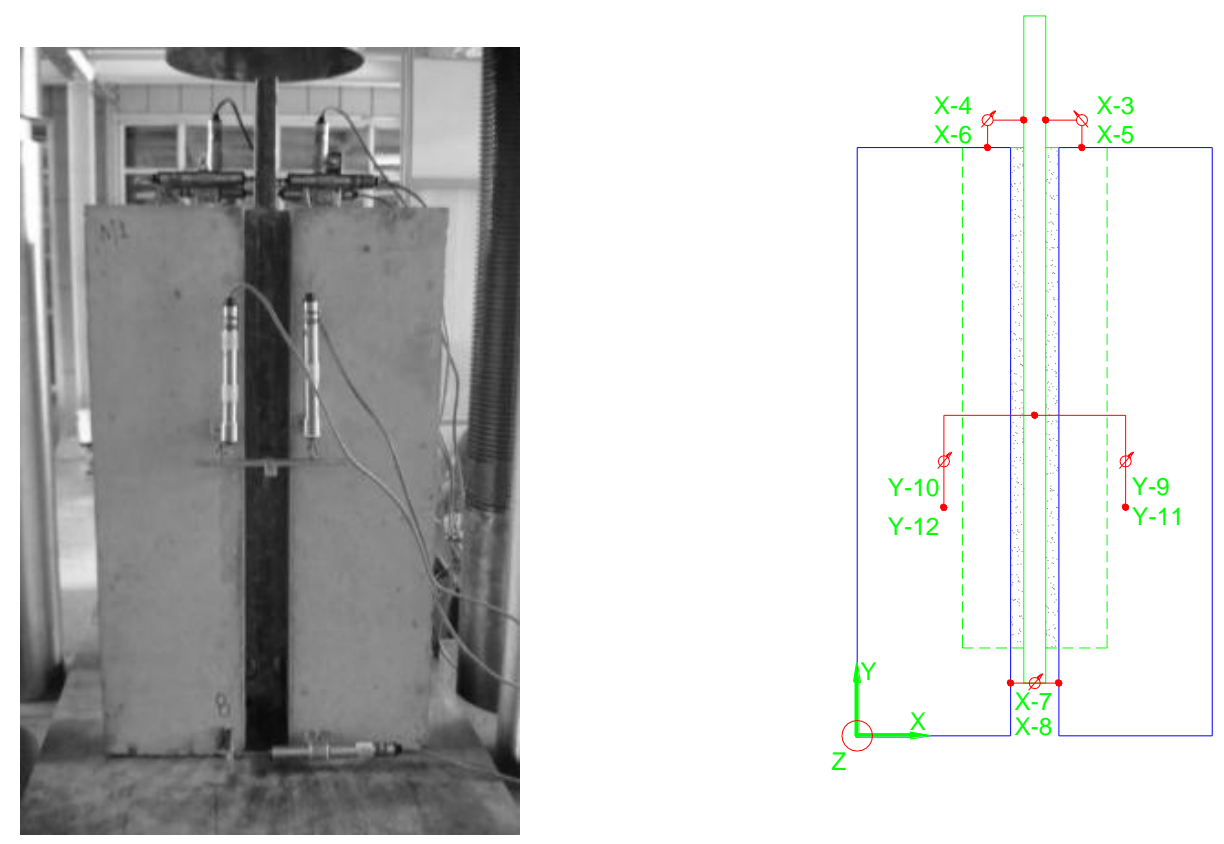

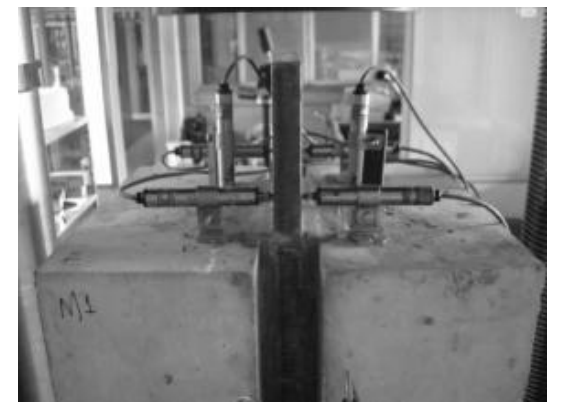

(a)

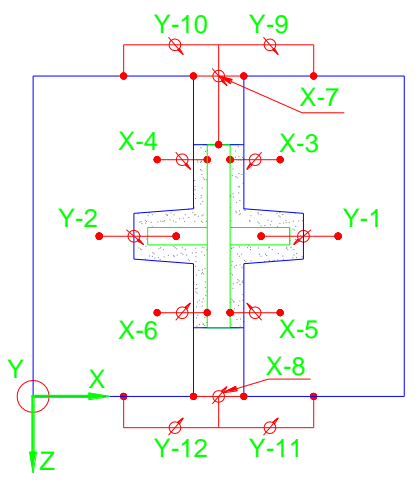

(b)

Figure 8 - (a) Overview of the test instrumentation; (b) Position of transducers.

\subsection{Results and discussion}

Before the presentation of results it is important to identify the failure modes that can possibly occur on the test in question. As can be seen in Figure 9 there are three interfaces involved in the connection by adhesion, interlocking and friction proposed: Interface 01 - between concrete and HPM, Interface 02 - between the connector and HPM and Interface 03 - between flange and HPM. 


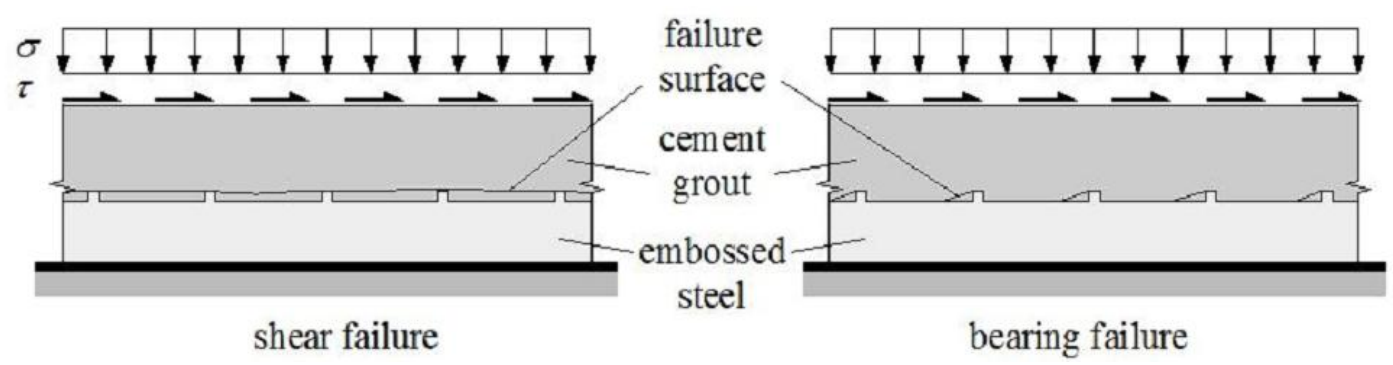

(a)

INICIAL CONFIGURATION

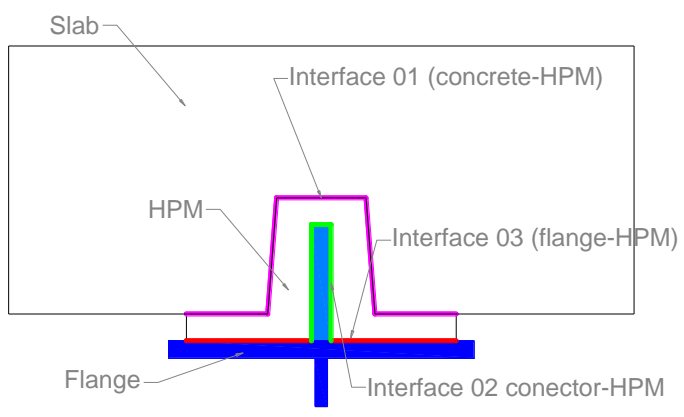

(b)
DEFORMED CONFIGURATION

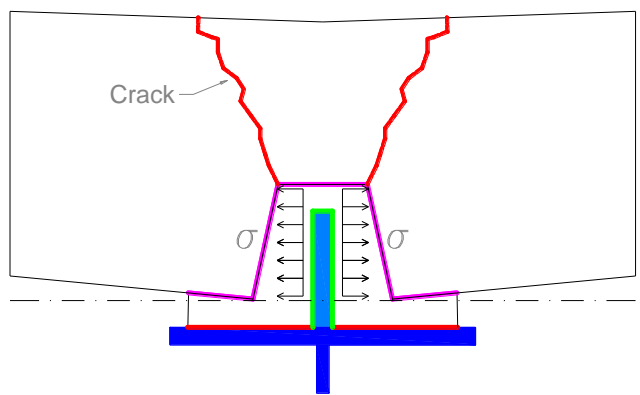

(c)

Figure 9 - (a) Shear and bearing failure in an embossed steel-cement grout interface [2]; (b) Initial configuration; (c) Post-peak configuration.

Relative slip can develop between each of the elements that compose the enumerated interfaces. Slip results from the shear stresses that are generated with loading. Failure usually occurs when the slip values are high. There are two possible modes of failure for the embossed steel-cement grout interfaces, as observed by Kitoh [21], and one type for the other two interfaces. For the embossed steel-cement grout interface (interface 02) these types are the bearing failure and the shear failure (Figure 9.a). For interfaces 01 and 03, the failure occurs basically by shear, which takes place inside the HPM which is interlocking with the asperities of the rough interface, for the rough concrete [4]. 
An additional mode of rupture is the failure of concrete block (slab), in cases of insufficient transversal reinforcement, due to the tensile stresses that appears in the connector region (Figure 9.b and Figure 9.c).

It is function yet of the relative slip between each of the elements that compose the enumerated interfaces, the transversal separation of interfaces, to this phenomenon is given name uplift. The deformation of the prototype is a result of the combined effect of slip and uplift, thus to describe the deformed configuration it is important capture this data. The deformed configuration can even be used as factors for comparison with previous studies [3], [4] in the field. Thereby, indicating that the proposed connection develops similar mechanisms of resistance of these researches.

\subsubsection{Stage 1}

Figure 10 presents the post-failure conditions of the prototypes tested in STAGE 1. For the prototypes $\mathrm{P} 03, \mathrm{P} 04, \mathrm{P} 05$ and $\mathrm{P} 06$, the rupture of the concrete block was crucial to the maximum load bearing capacity measured.

The brittle behavior observed during failure is conditioned by the plain concrete block. This sudden failure at the concrete block makes it difficult to determine the sequence of interface failures. However, prototypes P01 and P02 present a larger and more "ductile" load-slip behavior, enabling to identify the sequence of failure of interfaces, as show in Figure 10. The sequence of interface failure identified in prototypes P01 and P02 is: connector-HPM interface $\rightarrow$ flange-HPM interface $\rightarrow$ concrete-HPM interface (see Figure 9). For the rest of prototypes tested at STAGE 1, P03 to P06, the failure of plain concrete block makes it very difficult to establish the sequence of interface failure 


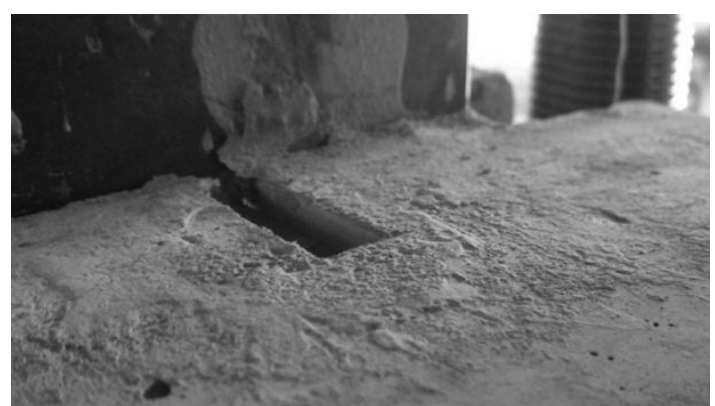

(a)

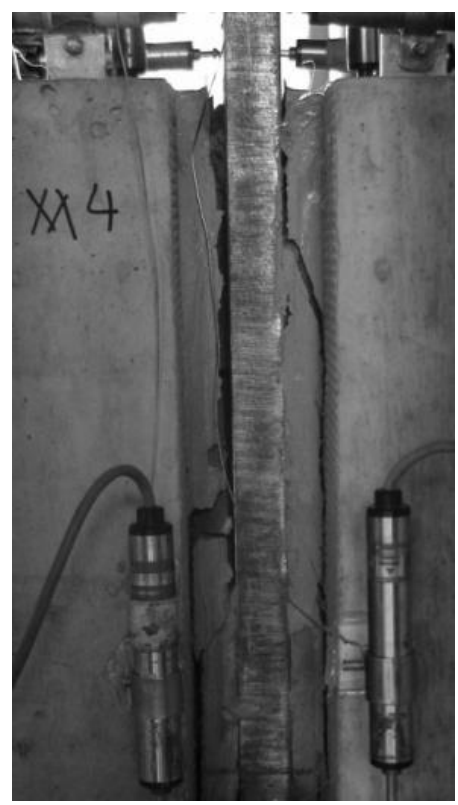

(c)

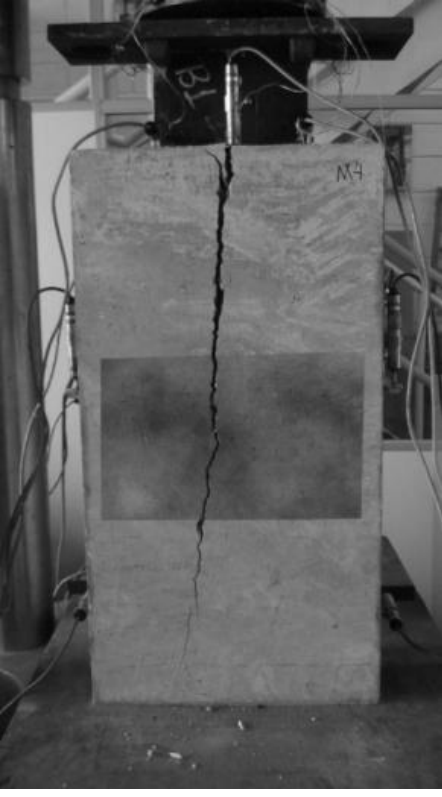

(d)

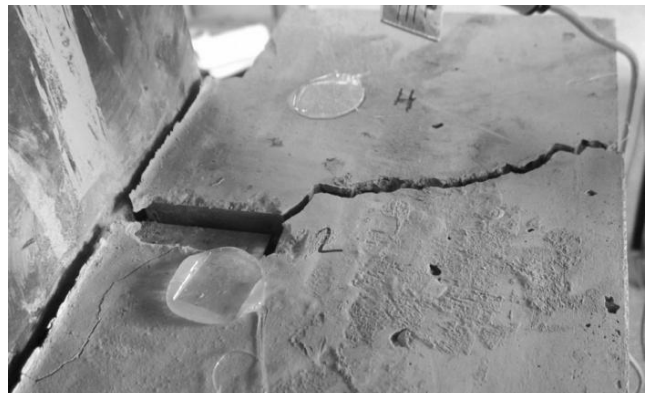

(b)

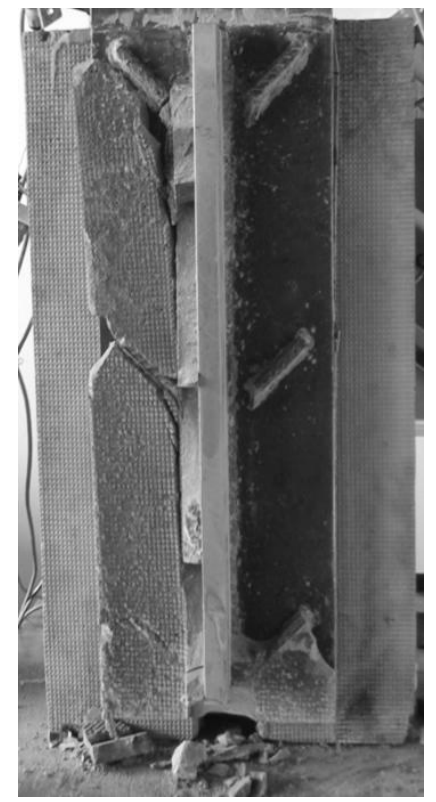

(e)

Figure 10 - Failure surfaces: (a) Interface connector-HPM; (b) Failure at the plain concrete block - crack orientation on the cross section; (c) Interface flange-HPM and in the HPM layer; (d) Failure at the plain concrete block - crack orientation on the top layer of the concrete slab; (e) Autopsy of specimen 02 - Stage 1 - Combined shear and bearing failure.

Table 2 presents de numerical values of maximum load capacity, slip value at the peak load extracted from Figure 11 and the characteristic slip, calculated according the Brazilian code ABNT-NBR 8800:2008 [22], for both stages. 
Table 2 - Main results obtained in push-out tests with $\mathrm{L}, \mathrm{R}$ and $\mathrm{RP}$ connectors

\begin{tabular}{|c|c|c|c|c|c|c|c|}
\hline & Prototype & $\begin{array}{c}\text { Connector } \\
\text { type }\end{array}$ & $\begin{array}{c}\boldsymbol{F}_{\text {máx }}{ }^{*} \\
{[\mathrm{kN}]}\end{array}$ & $\begin{array}{l}\text { Slip*** } \\
{[\mathrm{mm}]}\end{array}$ & $\begin{array}{c}\boldsymbol{\delta}_{\boldsymbol{u}} \\
{[\mathrm{mm}]}\end{array}$ & $\begin{array}{c}\boldsymbol{\delta}_{\boldsymbol{k}} \\
{[\mathrm{mm}]}\end{array}$ & $\begin{array}{c}\text { Average } \\
\text { Slip } \\
{[\mathrm{mm}]}\end{array}$ \\
\hline \multirow{6}{*}{ 荡 } & 01 & $\mathrm{~L}$ & 356.55 & 0.31 & 0.41 & 0.37 & -- \\
\hline & 02 & $\mathrm{~L}$ & 680.14 & 0.70 & 1.32 & 1.18 & -- \\
\hline & 03 & $\mathrm{R}$ & 790.33 & 0.33 & 0.57 & 0.51 & -- \\
\hline & 04 & $\mathrm{R}$ & 566.96 & 0.07 & 0.16 & 0.14 & -- \\
\hline & 05 & $\mathrm{RP}$ & 637.01 & 0.62 & 0.77 & 0.69 & -- \\
\hline & 06 & $\mathrm{RP}$ & 911.20 & 0.65 & 1.28 & 1.11 & -- \\
\hline \multirow{6}{*}{ 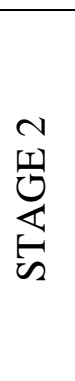 } & 07 & $\mathrm{~L}$ & 536.70 & 0.60 & 1.09 & \multirow{2}{*}{0.98} & \multirow{2}{*}{1.12} \\
\hline & 08 & $\mathrm{~L}$ & 609.36 & 0.64 & 1.15 & & \\
\hline & 09 & $\mathrm{R}$ & 620.34 & 0.26 & 0.50 & \multirow{2}{*}{0.45} & \multirow{2}{*}{0.58} \\
\hline & 10 & $\mathrm{R}$ & 685.21 & 0.34 & 0.67 & & \\
\hline & 11 & $\mathrm{RP}$ & 708.98 & 0.38 & 0.72 & \multirow{2}{*}{0.39} & \multirow{2}{*}{0.55} \\
\hline & 12 & $\mathrm{RP}$ & 682.43 & 0.18 & 0.43 & & \\
\hline
\end{tabular}

*Value supported by the entire specimen; ** Corresponding to $F_{\text {máx }}$.

In general the evolution of the load x slip curves presented in Figure 11, showed a very stiff initial branch, presenting slip values that are less than $1 \mathrm{~mm}$, until the maximum load is reached. From the maximum load on, a marked loss of load capacity associated with the addition of slippage can be observed. Thus a typical curve of failure of a connection by adhesion, interlocking and friction is show in Figure 11.

As expected, the RP-type connector showed the highest mean value for the maximum load capacity, but there is high variability associated with this result, as can be identified in Figure 11.a and Table 2. This variability is due to the asymmetric behavior observed in the prototypes P01, P04 and P05. 


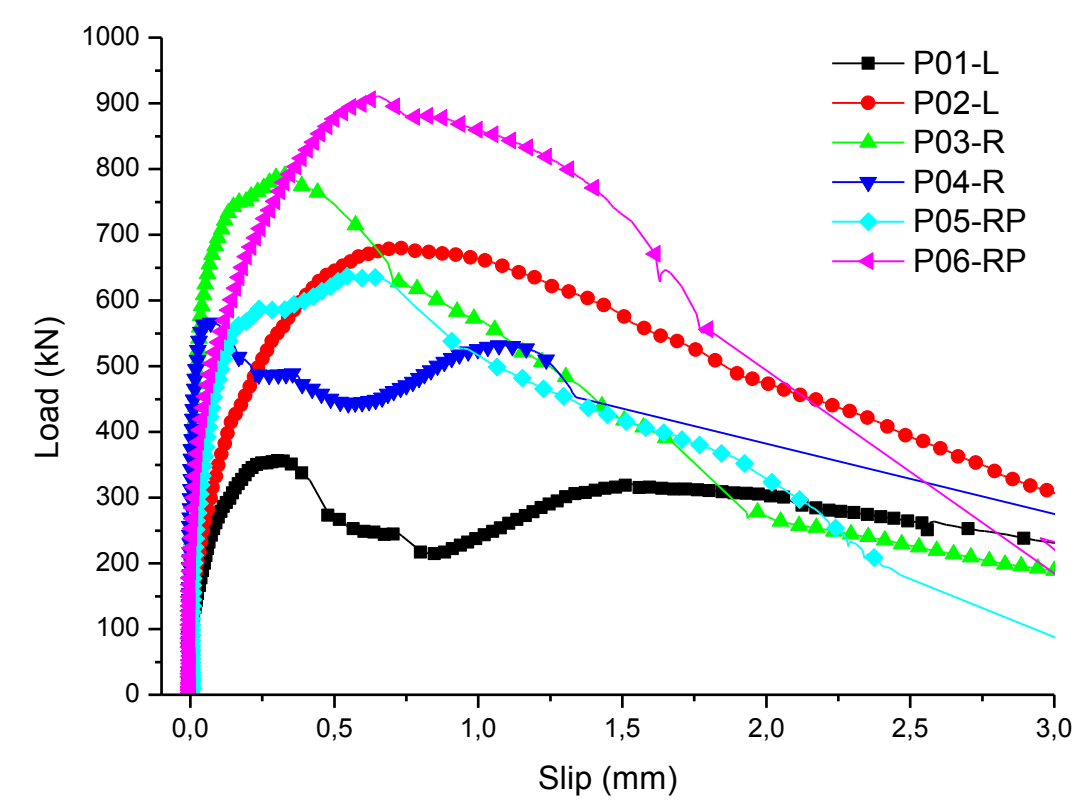

(a)

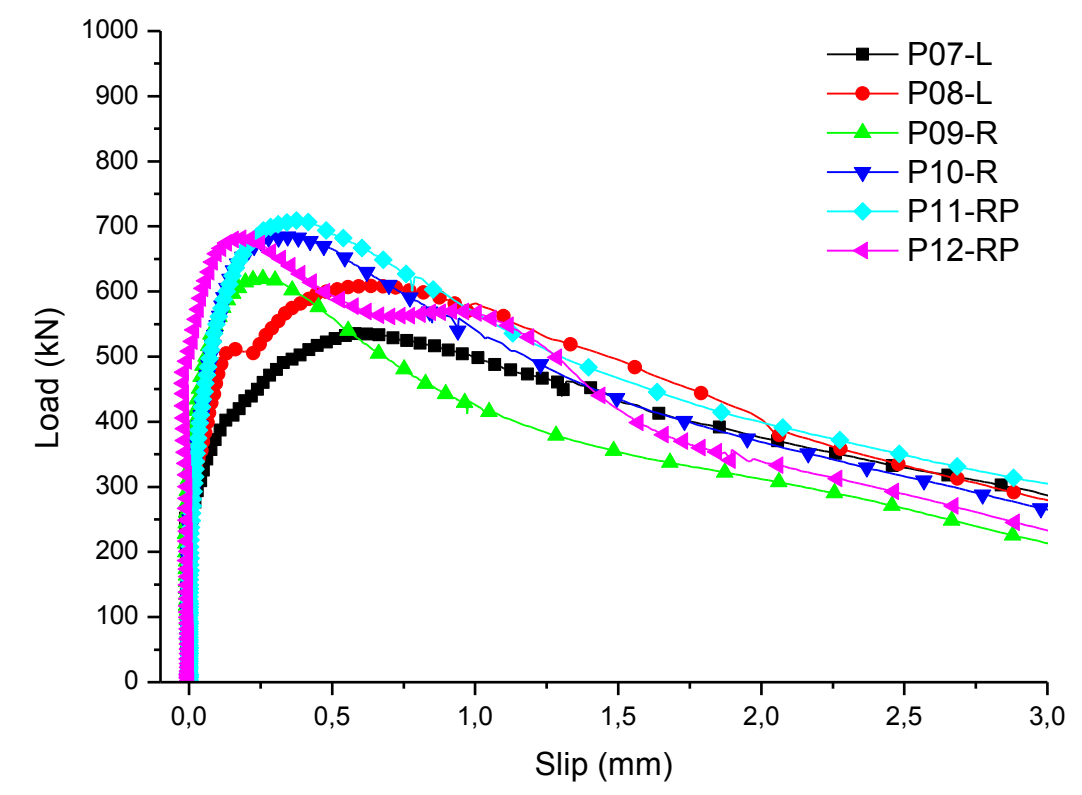

(b)

Figure 11 -Load $\times$ Slip values: (a) Specimens tested in Stage 1; (b) Specimens tested in Stage 2.

At a given time of the test, the prototypes in STAGE 1 were affected by a progressive loss of load capacity and then a resumption of the load capacity. This occurrence may be associated with the opening of a large crack in only one slab of the prototype, which certainly compromised its global resistance, by reducing the load capacity to almost half, 
when compared to the prototypes in which the asymmetric behavior did not occur, like P02, P03 and P06.

Factors such as, bad positioning of the metallic element (connector and reaction plate) during grouting, any eccentricity at the point of load application and variability in materials (concrete or HPM) may have been responsible for the asymmetric behavior of the prototypes P01, P04 and P05. It should be noted that based on the posterior autopsy of all prototypes, no evidence of voids in the HPM was found.

At the end of STAGE 1, a comparison between the results obtained with the RP-type connector (P05 and P06 prototypes) and the push-out prototypes tested by Thomann [3] is performed. Thus it is revealed that the RP connector is able to reach values of maximum load that are near the lower limit of load capacity obtained in the prototypes tested by Thomann [3].

The comparison was performed for the prototypes of PRH-33 series (Figure 12), which more closely resemble those of this investigation, since they have a similar geometry concrete block, connector and presence of an adhesive layer on the top flange - and similar strength of the materials involved in the connection (concrete quality C40/50, steel plate BRI 8/10 - S235 and mortar strength between 90 to $120 \mathrm{~N} / \mathrm{mm}^{2}$ ). 


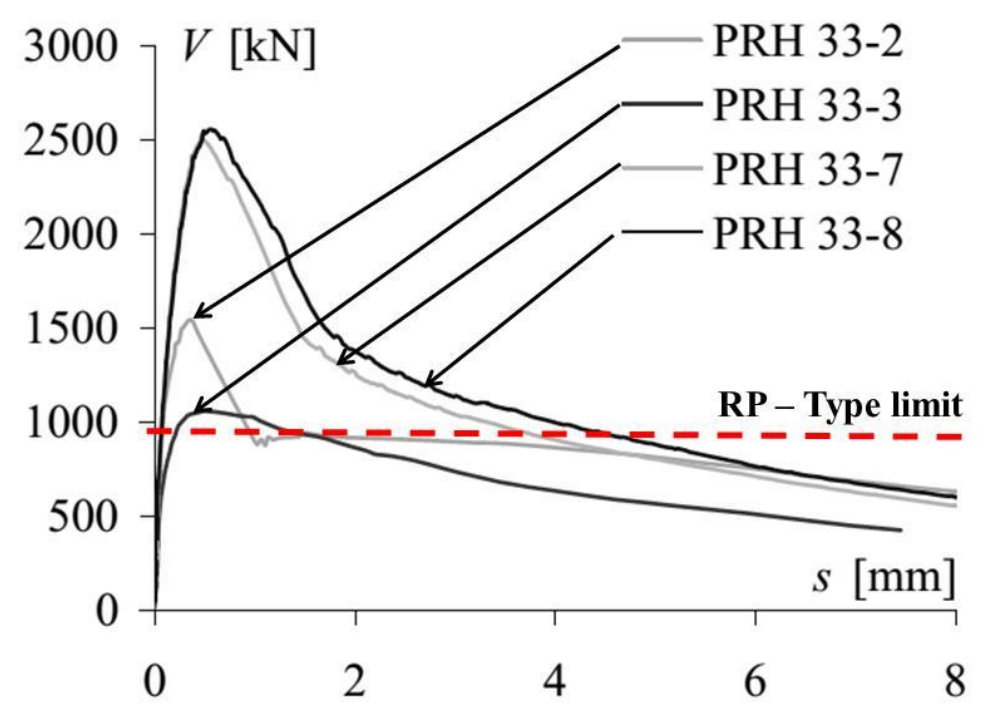

Figure 12 - Load-slip curves obtained by Thomann [3] with prototypes PRH 33 compared to RP-type load limit.

It should be noted that according to Eurocode 4 [17] none of the tested connectors at this stage can be considered as ductile, since they do not reach the $6 \mathrm{~mm}$ of characteristic slip, $\delta_{k}$. Similar behavior was obtained by Thomann [3] in his push-out tests.

\subsubsection{Stage 2}

The tests performed in STAGE 1 allowed to clarify several issues related to the experimental setup and to demonstrate that the proposed interfaces are promising in terms of load capacity. This section presents the results obtained in STAGE 2 of the experimental tests. Here, the mechanical properties of the used materials were standardized and reinforced concrete was used to manufacture the block. 
- Post-failure status

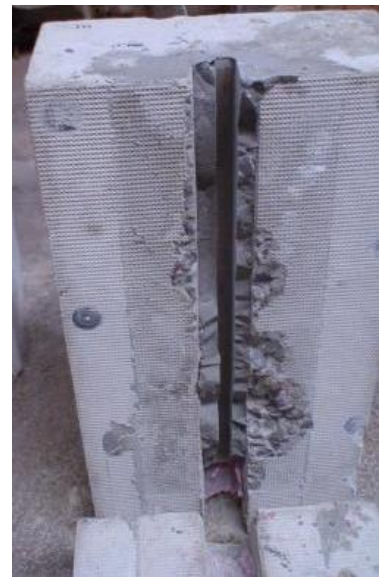

(a)

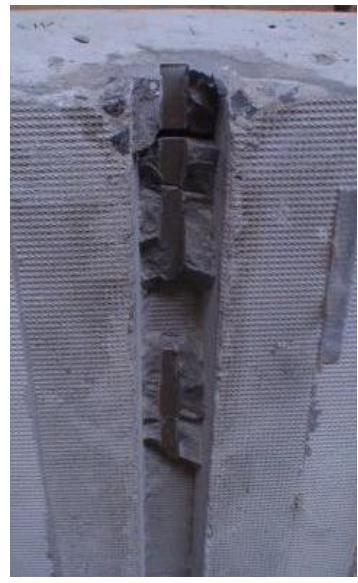

(b)

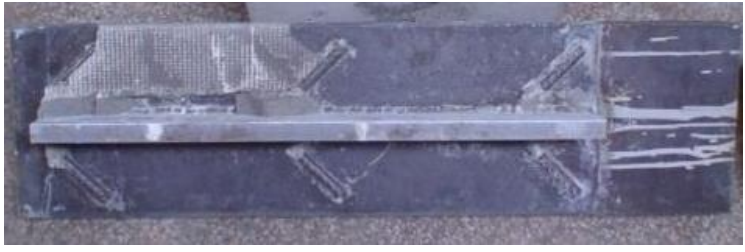

(c)

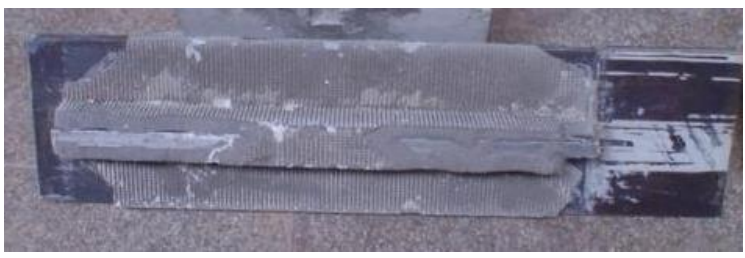

(d)

Figure 13 - Post-failure status: (a) concrete block L-type connector; (b) concrete block R -type connectors; (c) metallic part of L-type connector; (d) metallic part of RP-type connectors

Figure 13 presents the post-failure status of some specimens tested during STAGE 2. As can be seen, the great amount of HPM fixed to the concrete block in the region of the rib Figure 13.a and a small amount of HPM attached to the L-type connector, Figure 13.c indicates that the weakest interface in the connection using L-type embossment was the Interface 02 (connector-HPM) . In the connectors of type R and type RP, the observed behavior is rather different, because most of the HPM layer remains attached to connector, as presented in Figure 13.d and only a small portion of HPM is attached to the concrete block, indicating that the Interface 01 was the weakest interface.

Differently from the STAGE 1, the concrete block failure did not occur. Micro cracks appeared in the top of the specimen, but no severe damage occurred in the reinforced concrete block. 
As expected, again the RP connectors showed the average highest load capacity. Figure 11.b presents the evolution of load capacity and slip, measured at the top of the specimen, and Table 2 summarizes the main results obtained.

Comparing the results obtained in R-type and in RP-type specimens tested in STAGE 2, it is noticed that there is an increase of $6.57 \%$ in the average maximum load for the second group of specimens. However, a reduction of $13.33 \%$ in the value of characteristic slip, $\delta_{k}$, calculated according to Eurocode 4 [17], is also verified. It should be noted that $\delta_{\mathrm{uk}}$ corresponds to the lower value of $\delta_{\mathrm{u}}$ (slip capacity of a sample measured for the level of characteristic load i.e $90 \%$ of the peak load) obtained in a group of 3 specimens and reduced of $10 \%$.

If the comparison is established in terms of average slip value at maximum load, it can be seen that the behavior is similar, since in average measured slip is $0.30 \mathrm{~mm}$ in R-type and $0.28 \mathrm{~mm}$ in RP-type specimens.

When evaluating the results obtained with the L-type connectors, it is observed that they show a surprising high load capacity that corresponds to about $82.4 \%$ of the maximum load measured RP-type specimens. In addition, the L-type specimens present higher deformation capacity than R-type or RP-type prototypes.

Thus the results obtained with L-type specimens indicate that about $20 \%$ of the load capacity comes from the embossed steel connector, once the L-type specimens were manufactured with the same geometry and materials of others, type R and RP, with exception to the presence of roughness (and/or holes) on the connector surface. 
- Behavior uplift x slip

Figure 14 illustrates the uplift $x$ slip relationship. In this case, the uplift is the transversal separation between the steel connector and the concrete block, measured at top and bottom of the specimen. This parameter can be considered as a measure of connection dilatancy.

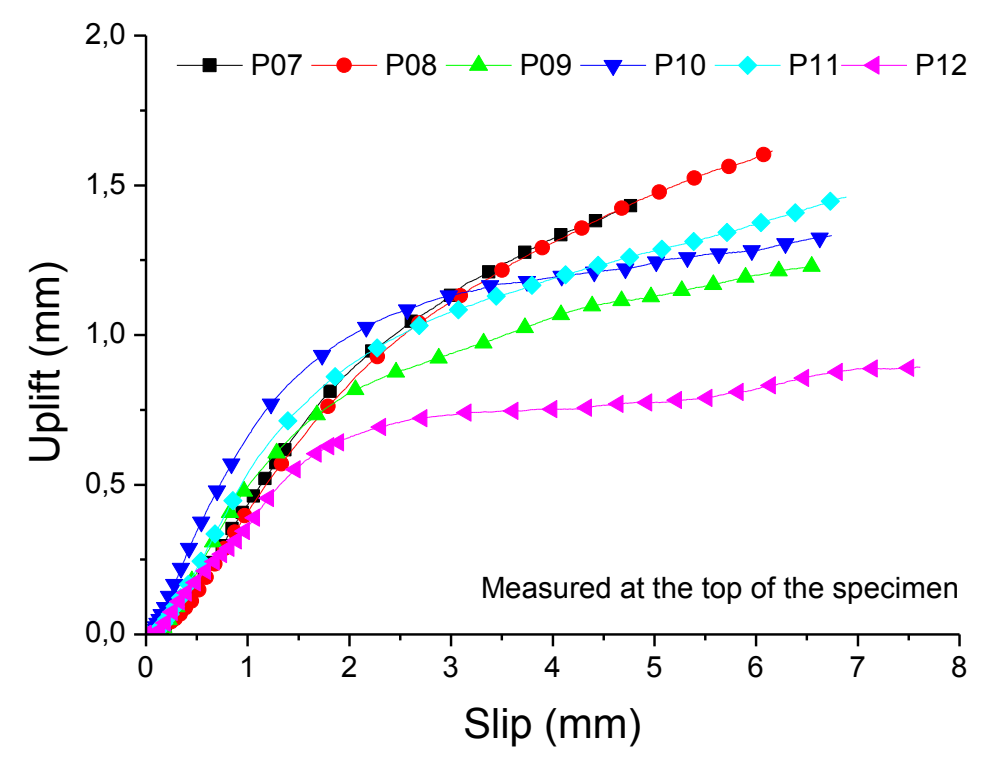

(a)

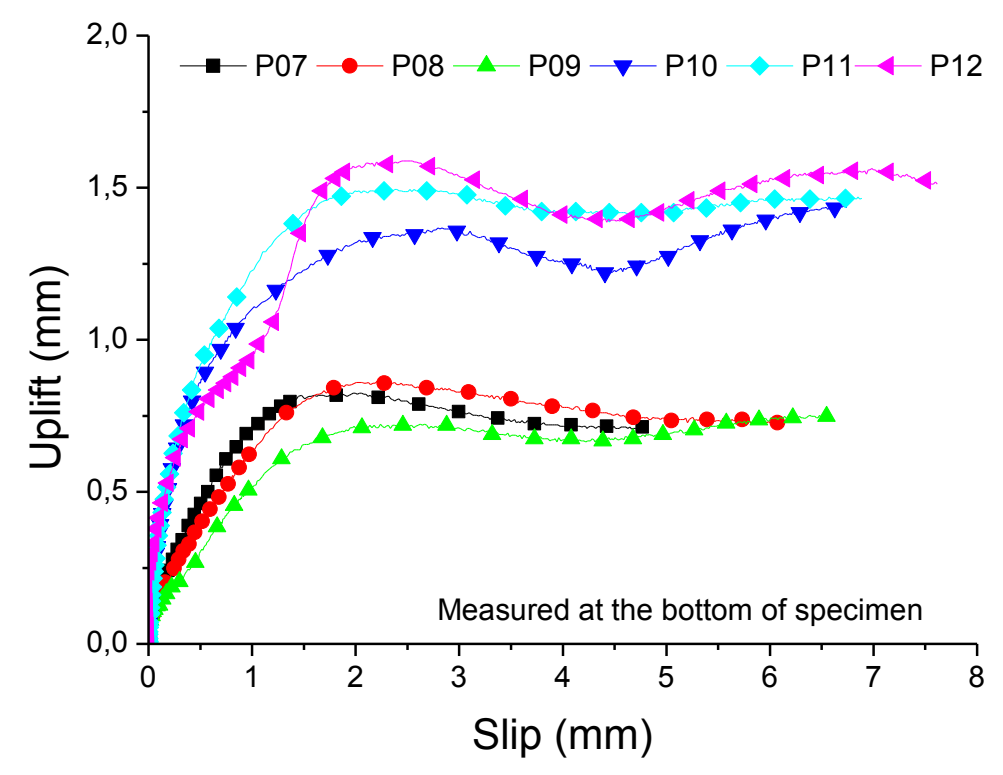

(b)

Figure 14 - Results - Uplift x Slip - STAGE 2: (a) measured at the top of specimen; (b) measured at the bottom of specimen; 
The uplift in the connection presents relatively low values before the maximum load is attained, always less than $0.2 \mathrm{~mm}$, which are similar to the values of uplift measured by Thomann [3] and Papastergiou [4]. After the maximum load is attained, the uplift value reaches a plateau about $0.5-1.5 \mathrm{~mm}$ for both situations of measurement. This value is achieved at about 6-8.0 mm of average slip in the connection. It stands out that for the Ltype specimens, the uplift at the top of the model is more relevant when compared to the $\mathrm{R}$ and RP-type connectors. However the opposite occurred in the measurement at the base of the model. Probably the reason for the second case is a lower ductility of the specimen, which provides a beginning of the uplift more intense.

The average relations uplift x slip extracted from Figure 14- (a) is presented in equations 1 to 3. These expressions refers to the L-type, R-type and RP-type connectors respectively:

$$
\begin{aligned}
& \text { Uplift }=-0,00212 \cdot \text { Slip }^{3}-0,0343 \cdot \text { Slip }^{2}+0,51374 \cdot \text { Slip }-0,04391 \\
& \text { Uplift }=0,01123 \cdot \text { Slip }^{3}-0,15135 \cdot \text { Slip }^{2}+0,71457 \cdot \text { Slip }-0,02407
\end{aligned}
$$

According to Eurocode 4 [17], Annex B, where the connector is composed of two separate elements, one to resist longitudinal shear and the other to resist forces tending to separate the slab from the steel beam, the ties which resist separation shall be sufficiently stiff and strong so that separation in push tests, measured when the connectors are subjected to $80 \%$ of their ultimate load, is less than half of the longitudinal movement of 
the slab relative to the beam. Thus, from the analysis of Figure 11 and Figure 14, it can be inferred that the values for the uplift were not relevant in the context of Push-out test.

\subsubsection{Comparison of load capacity between the tested specimens, Thomann [3] results and other commonly used shear connectors and}

In this section will be presented a comparative analysis between the resistance obtained from the analyzed connectors and those obtained with other common shear connectors such as headed studs and U-laminates.

To determine the ultimate strength of the connectors, the requirements of ABNT - NBR 8880: 2008 [22], were applied, considering the concrete compressive strength of $45 \mathrm{MPa}$ and the ultimate tensile strength of the connector as $415 \mathrm{MPa}$. The NBR 8800 standard provides equations to calculate the nominal resistance of headed studs connectors, fully embedded in concrete, based on the lower values obtained among the following two values,

$Q_{R d}=0,5 A_{c s} \sqrt{f_{c k} E_{c}} \quad$ Eq. 4

$Q_{R d}=R_{g} R_{p} A_{c s} f_{u}$

Eq. 5

Where, $A_{c s}=$ connector cross section; $f_{u}=$ ultimate tensile strength of steel; $f_{c k}=$ characteristic resistence of concrete; $E_{c}=$ elasticity modulus of concrete; $R_{g}$ and $R_{p}=$ factors that consider the reduction in resistance when studs are used in connecting slabs with embedded steel formwork. To cast-in-place slabs both factors are equal 1.0.

To calculate the nominal resistance of the U-laminated connectors, ABNT - NBR 8880: 2008 [22] provides Equation 6, 
$Q_{R d}=\frac{0,3\left(t_{f c s}+0,5 t_{w c s}\right) L_{c s} \sqrt{f_{c k} E_{c}}}{\gamma_{c s}}$

Eq.6

Where, $t_{f c s}=$ thickness of connector flange mesured from half length between the free edge and the adjacent face of the web ; $t_{w c s}=$ thickness of connector web; $L_{c s}=$ length of U-laminated profile; $\gamma_{c S}=$ safety factor.

The comparison is performed upon the maximum load value obtained by the RP connector and expressed in terms of load per meter. This parameter can be obtained by dividing the specimen maximum load capacity by the total length of the connector, which in this case is equal to $1.14 \mathrm{~m}(2 \times 0.57 \mathrm{~m})$.

Table 3 presents the values of load capacity calculated for each type of connector in analysis (headed studs and U-laminated) and indicates their number, per meter that correspond to L-type, R-type or RP-type connectors studied within the present research.

It can be concluded from Table 3 that to achieve the same load capacity that is obtained with the RP connector, a high number of connectors/meter is necessary in most of the cases. It should also be noted that the continuity of the connectors contributes to increase the stiffness of the steel section and therefore, the stiffness of the composite element.

Table 3 - Load capacity of headed studs and U-laminated connectors

\begin{tabular}{|c|c|c|c|c|c|c|c|}
\hline \multirow[b]{2}{*}{ Type } & \multirow[b]{2}{*}{ Image } & \multirow{2}{*}{$\begin{array}{l}\text { Diameter } \\
\text { (d) }\end{array}$} & \multirow[b]{2}{*}{$\begin{array}{c}\text { Thickness } \\
\text { (mm) }\end{array}$} & \multirow{2}{*}{$\begin{array}{l}\text { Load capacity / } \\
\text { connector } \\
\text { NBR } 8800 \\
(\mathrm{kN})\end{array}$} & \multicolumn{3}{|c|}{ Connectors / Length } \\
\hline & & & & & $\begin{array}{c}\mathrm{L} \\
(502.4) \\
\mathrm{kN} / \mathrm{m}\end{array}$ & $\begin{array}{c}\mathrm{R} \\
(572.6) \\
\mathrm{kN} / \mathrm{m}\end{array}$ & $\begin{array}{c}\mathrm{RP} \\
(610.3) \\
\mathrm{kN} / \mathrm{m}\end{array}$ \\
\hline \multirow{3}{*}{ Stud } & & 16 & - & 96.4 & 6 & 6 & 7 \\
\hline & & 19 & - & 135.9 & 4 & 5 & 5 \\
\hline & $n_{11}$ & 22 & - & 182.3 & 3 & 4 & 4 \\
\hline
\end{tabular}




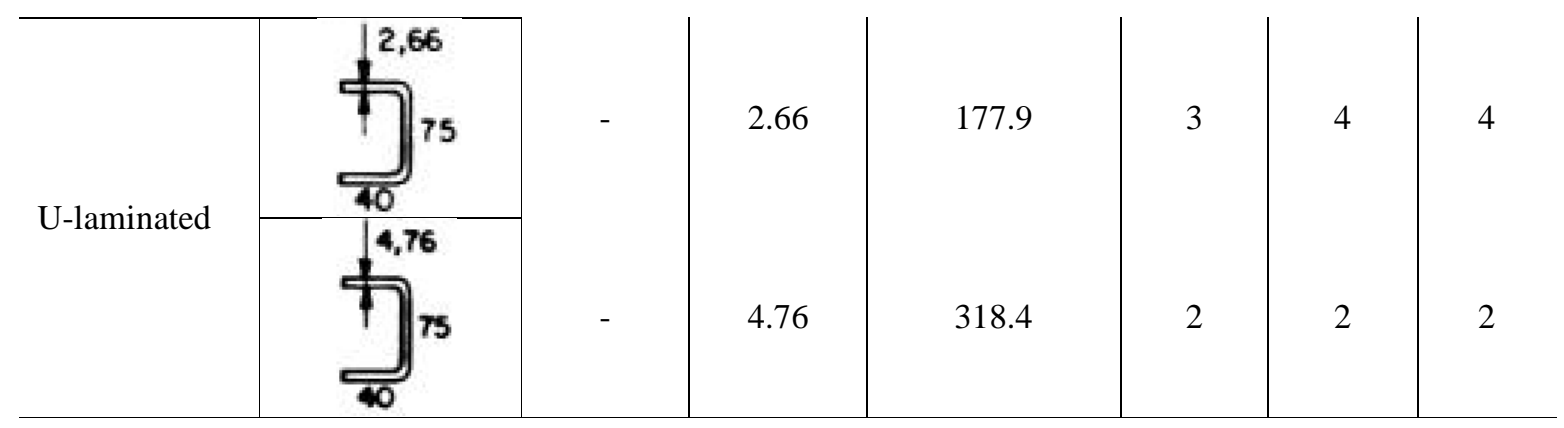

Once again, a comparison is established between the load capacity values obtained with the RP-type connector and obtained by Thomann [3] in similar specimens. It is verified that the load capacity measured in Thomann [3] specimens are two to four times greater than those obtained in STAGE 2 of the present experimental program. It is believed that this difference in load capacity must be fundamentally caused by the presence of a"bond layer" on the surface of the flange and an increased roughness on the surface of the concrete block that were both guaranteed in Thomann [3] work.

The roughness adopted for the lower flange and the concrete block in the present work is result of the search for a faster, more practical, cheaper and easier method of manufacture. This option implies in a lower roughness and thus in a smaller contribution of friction to the resistance of the connection.

However, it is important to note that the focus of the previous works [11] and [12] was the application of this connection, in steel and concrete composite bridge decks, where a very high load capacity is needed. Thus, it is understood that the resistance achieved by the type RP connector is very high in the context of a conventional comercial or residencial building, which is the focus of the present research. 


\section{CONCLUSIONS}

In the course of the development of this work, it was sought to characterize the strucutral behavior and quantify of the resistance of a new proposal of connection by adhesion, interlocking and friction by using an experimental approach and providing preliminary data for the design of the proposed connection. The results obtained indicate that the proposed steel-concrete connection between precast reinforced concrete slabs and steel girders seems to be a promising solution. Fast erection and increased durability are major advantages of the solution and, more relevant, high shear strength values were obtained during the tests performed within this work. These values, when compared to the results obtained with usual connectors, like headed studs ot U-laminated connectors, show that the proposed connection load capacity is much higher. However, the proposed connection can not be characterized as ductile. Regarding this parameter, ductility, futher studies should be performed in order to improve this behaviour if it is relevant to submit the connection to very high load levels which is usually not the case., It is important to consider that previous studies have established that the connection by adhesion, interlocking and friciton exhibits high stiffness, sufficient static and fatigue resistance, and adequate deformation capacity, allowing the formation and design of ductile composite structural elements [1], it is important to caraterize the proposed conection submitted to cyclic loads. Finally the main remarks are drawn from this work:

- The roughness of the concrete slab was a limiting factor for the resistance, probably a more rough interface would result in much more significant values of the connection strength. This may have been responsible for the small difference in strength obtained when comparing type connectors R and RP. 
- In the context of push-out tests, it should be noted that the presence of the hole in the connector RP, did not cause significant increase in the resistance of the experimental prototype. A smaller hole diameter, as compared to usual Perfobond connectors, may have contributed to this result.

- The results obtained for the L-type specimens indicate that about $20 \%$ of the load capacity comes from the embossed steel connector.

\section{ACKNOWLEGMENTS}

The authors thank the federal agency CAPES and the Foundation for Research Support of the state of Sao Paulo, Brazil (FAPESP) for providing a PhD scholarship, and the University of Minho, in Portugal, for the international collaboration.

\section{REFERENCES}

[1] D. Papastergiou and J.-P. Lebet, "Design and experimental verification of an innovative steel-concrete composite beam," J. Constr. Steel Res., vol. 93, pp. 919, Feb. 2014.

[2] M. Thomann and J.-P. Lebet, "The modelling of an embossed steel-to-cement paste confined interface loaded in shear," J. Constr. Steel Res., vol. 63, no. 5, pp. 639-646, May 2007.

[3] M. Thomann, "Connexions par adhérence pour les ponts mixtes acier-béton," École Polytechnique Fédérale de Lausanne, 2005.

[4] D. Papastergiou, "Connections by Adhesion, Interlocking and Friction for SteelConcrete Composite Bridges under Static and Cyclic Loading," École Polytechnique Fédérale de Lausanne, 2012.

[5] C.-S. Shim, P.-G. Lee, and S.-P. Chang, "Design of shear connection in composite steel and concrete bridges with precast decks," J. Constr. Steel Res., vol. 57, no. 3, pp. 203-219, Mar. 2001.

[6] J. Studnicka, J. Machacek, A. Krpata, and M. Svitakova, "Perforated shear connector for composite steel and concrete beams," in Composite Construction in Steel and Concrete IV, 2002, no. 4, pp. 367-378. 
[7] E. Baran and C. Topkaya, "An experimental study on channel type shear connectors,” J. Constr. Steel Res., vol. 74, pp. 108-117, Jul. 2012.

[8] S.-H. Kim, K.-T. Choi, S.-J. Park, S.-M. Park, and C.-Y. Jung, "Experimental shear resistance evaluation of Y-type perfobond rib shear connector," J. Constr. Steel Res., vol. 82, pp. 1-18, Mar. 2013.

[9] V. Schmitt, G. Seidl, M. Hever, and C. Zapfe, "Verbundbrücke PöckingInnovative VFT-Träger mit Betondübeln," Stahlbau, vol. 73, no. 6, pp. 387-393, Jun. 2004.

[10] P. C. G. da S. Vellasco, S. A. L. de Andrade, L. T. S. Ferreira, and L. R. O. de Lima, "Semi-rigid composite frames with perfobond and T-rib connectors Part 1: Full scale tests," J. Constr. Steel Res., vol. 63, no. 2, pp. 263-279, Feb. 2007.

[11] G. Veríssimo, "Desenvolvimento de um conector de cisalhamento em chapa dentada para estruturas mistas de aço e concreto e estudo do seu comportamento," ... Pós-graduação em Eng. Estruturas, 2004.

[12] F. Leonhardt, W. Andrä, H.-P. Andrä, and W. Harre, "Neues, vorteilhaftes Verbundmittel für Stahlverbund-Tragwerke mit hoher Dauerfestigkeit.," Betonund Stahlbetonbau, vol. 82, no. 12, pp. 325-331, Dec. 1987.

[13] Fib - Fédération internationale du Béton, fib Model Code for Concrete Structures 2010, no. September. 2013, p. 434.

[14] J.-P. Lebet, "New Steel-Concrete Shear Connection for Composite Bridges," Compos. Constr. Steel Concr., pp. 6-6, 2008.

[15] M. U. . Oguejiofor, E. C.; Hosain, "A parametric study of perfobond rib shear connectors," Can. J. Civ. Eng., vol. 21, pp. 614-625, 1994.

[16] M. U. . Oguejiofor, E. C.; Hosain, "Numerical analysis of Push-Out specimens with Perfobond rib connectors," Comput. Struct., vol. 62, pp. 617-624, 1996.

[17] European Committee for Standardization., "EUROCODE 4: Design of composite steel and concrete structures - Part 1.1: General rules and rules for buildings," Brussels, 2004.

[18] R. D. Vanderlei and J. S. Giongo, "Análise experimental do concreto de pós reativos: dosagem e propriedades mecânicas," Cad. Eng. Estruturas, vol. 8, no. 33, pp. 115-148, 2006.

[19] ABNT - ASSOCIAÇÃO BRASILEIRA DE NORMAS TÉCNICAS., "NBR 8522:2008 - Concrete - Determination of the elasticity modulus by compression," ABNT, Rio de Janeiro, 2008. 
[20] ABNT - ASSOCIAÇÃO BRASILEIRA DE NORMAS TÉCNICAS., "NBR 7222: 2011 - Concrete and mortar - Determination of the tension strength by diametrical compression of cylindrical test specimens," Rio de Janeiro, 2011.

[21] H. Kitoh and K. Sonoda, "Bond characteristics of embossed steel elements," Compos. Constr. Steel Concr. III, 1996.

[22] ABNT - ASSOCIAÇÃO BRASILEIRA DE NORMAS TÉCNICAS., "Projeto de estruturas de aço e de estruturas mistas de aço e concreto de edifícios," Rio de Janeiro, 2008. 